\title{
La puesta en escena del no saber y el rol del espectador en la posmodernidad: hacia un teatro emancipado como espacio de resistencia
}

Gabriela Luisa Javier Caballero

Universidad Nacional Mayor de San Marcos

\section{RESUMEN}

El saber del teatro es algo que radica en su propia naturaleza y los mecanismos que emplea para generar sentido. Ese saber no está referido a pasar ese "conocimiento» al espectador, sino se trata de un reconocimiento de que el otro tiene sus propias herramientas para decodificar y resignificar lo puesto en escena. En nuestra propuesta de trabajo partimos de la idea de que eso como tal ha de ir hacia el no saber, hacia lo real a través de los propios mecanismos teatrales para alejarse de lo estrictamente mimético. En ese sentido, el espectador, como sujeto ante la imagen, en la dinámica de escena/público, no ha de ser constituido como un objeto. Nos interesa enfatizar la idea de un espectador emancipado de acuerdo con los aportes de Rancière, y a partir de estos, de un teatro emancipado y de qué haría a este tal; a saber, el reconocimiento de la imposibilidad de la creación de un espectador, de la disolución de las dinámicas sujeto-objeto entre actor o creador y público, y la idea de que en este teatro se da un atravesamiento del fantasma lacaniano $(\$ \otimes \mathrm{a})$. De acuerdo con esto, estableceremos coordenadas que sitúan al teatro como un espacio de resistencia ante la globalización y la posmodernidad. Conjugamos para esto los aportes sobre el espectador y la teatrología de Jorge Dubatti con lo propuesto por Rancière acerca de la emancipación del espectador desde una perspectiva lacaniana, para acercarnos a la propuesta del teatro emancipado. 


\section{PALABRAS CLAVE}

Jorge Dubatti, Colectivo Teatral Viaexpresa, convivio teatral, posmodernidad, zapping, espectador emancipado, espectador compañero, transteatralización, expectación.

\section{ABSTRACT}

Knowledge of the theater is something that is rooted in its own nature and the mechanisms that are used to create meaning. Knowing is not referred to as transmitting that «knowledge» to the spectator, but rather, it is about the recognition that the other has his own tools to decode and give new meaning to that which is on stage. We have based our proposal on the idea that that(knowing) as such, must go towards not-knowing, towards that which is real through its own theatrical mechanisms to distance itself from that which is strictly mimetic. In this way, the spectator, as a subject in the presence of the image, in the dynamic of stage/audience must not be constituted as an object. We would like to emphasize the idea of an emancipated spectator according to Rancière's contributions, and based on these, of an emancipated theater which would make this, knowingly, the acknowledgement of the impossibility of the creation of a spectator, the breaking-up of the dynamics of subject-object, between actor or creator and audience and the idea that in this kind of theater there is a crossing over of the Lacanian ghost $(\$ \otimes a)$. Consistent with this, we establish coordinates that position the theater as a space of resistance against globalization and post modernity. Combining the contributions of the spectator and the theatrology of Jorge Dubatti with the proposals of Rancière regarding the emancipation of the specatator from the Lacanian perspective, we aim to have a closer look at emancipated theater.

\section{KEY WORDS}

Jorge Dubatti, Theatrical Collective Viaexpresa, theatrical co-existence, post modernity, channel-surfing, emancipated spectator, colleague spectator, trans-theatrilization, eagerness. 


\section{Introducción: sobre los espectadores y la posmodernidad}

Todos los seres humanos somos espectadores ante el mundo. No estamos ya en la época en que el hombre era actor no solo de su vida, sino también del transcurrir de la sociedad en tanto podía intervenir activamente en las diversas situaciones políticas o coyunturales que determinaban el rumbo de sus naciones. Actualmente la vida pasa frente a nosotros, el devenir rápido de las situaciones nos coloca en una posición de espectador constantemente, de modo que, si miramos, también somos objeto de la mirada del otro. La vida actual se traduce en usuales actos performáticos, en el sentido en que:

Para desempeñar(se) socialmente hay que saber actuar: dominar la producción de ópticas políticas o políticas de la mirada, especialmente delante de las cámaras. Se habla de transteatralización, teatralidad social, sociedad del espectáculo. [...] Se trata [de que] todo se ha espectacularizado. La palabra teatro es empleada en contextos no específicos (Dubatti 2007: 15) (cursivas en el texto, negritas nuestras).

Se trata de que la posmodernidad, con la consecuente espectacularización de la vida pública y privada, han determinado que el ritmo y los modos de vida cambien, y que los límites entre disciplinas se pierdan. Este es el caso, también, del teatro, que es empleado ya no en su contexto disciplinario, sino para hacer referencia a todo tipo de acciones en sociedad. Otras formas de espectación se dan ante el cine y la televisión: medios audiovisuales masivos y mediáticos que han formado espectadores en serie. Estar ante una película o ante un programa de televisión implica un tipo de mirada diferente que la que se da en el teatro; en el cine no se está viendo algo vivo, sino que el sujeto está ante una imagen ya grabada, que se repite función a función, y que bien podría ser cosificada por su condición de inamovible. En la televisión pasa algo muy parecido, pero con el adicional de la dinámica del zapping. En esta, la proliferación de imágenes es tal y se da a tal velocidad, que es imposible captar el contenido de todas. Si al inicio de la aparición de este aparato tecnológico se trataba de la importancia y el asombro ante la imagen, lo que deslumbra ahora es la velocidad y la capacidad de quien mira para - a través del poder que le concede el uso del control remoto-cambiar las imágenes a su disposición. El ejercicio del zapping parece una realización plena de la democracia, en la que el espectador es libre de elegir qué imágenes ver y cuáles no; sin embargo, esta libertad no es tal porque las producciones televisivas son seriales. La mayoría se produce bajo el mismo modelo y con la intención de perpetuar determinadas ideologías y de reproducir idearios sociales homogeneizantes (Sarlo 2004). 
El zapping re-crea la ilusión de igualdad y perpetúa el imaginario de los espectadores sujetos que viven en democracia, y anula las capacidades cuestionadoras del hombre, en tanto, como mecanismo producido - y apto para la época - continúa con la relación de sujeto/objeto por medio de la mirada (sería quizá mejor hablar de individuo/objeto).

Esta propuesta sostiene que el teatro es el medio de presentación/ representación propicio para huir de esos modos de construir un espectador uniforme. La espectación del teatro demanda un espectador emancipado pero a la vez compañero, en cuyo ejercicio se dé el quiebre de la relación cosificadora entre sujeto de la creación/sujeto de la escena y espectador; lo cual creará coordenadas propicias para combatir algunos males de la posmodernidad y de los sujetos. Para ello se emplearán en primera instancia los alcances de Jorge Dubatti sobre el teatro y la experiencia del convivio, y los relacionaremos con la propuesta de Rancière sobre el espectador emancipado para proponer el atravesamiento del fantasma lacaniano de la relación sujeto/objeto entre escena y espectador. Esto proporcionará las posibilidades para pensar al teatro y lo que este implica como un espacio de resistencia ante el influjo posmoderno en la mirada y en la sociedad.

\section{Ser teatro: problematicidad y condiciones}

Una de las cuestiones complicadas acerca del hacer teatral es su propia entidad problemática. El teatro es poseedor de una singularidad intrínseca a su estructura; empero, a la vez no hay una determinación de límites establecidos, pues actualmente la complejidad del teatro radica también en su desdelimitación; en la ampliación de la dramaticidad, y en las tensiones diversas entre los conceptos de arte y vida:

Se afirma que el teatro es uno de los fenómenos artísticos y humanos más completos y relevantes del mundo actual; sin embargo, ya no se sabe bien a qué llamar teatro [...] El teatro comparte esta entidad problemática con la del arte en general [...] se ha desdefinido; el teatro ya no es evidente. El ser del teatro necesita ser redefinido a partir de los cambios en las prácticas específicas y en la cultura (Dubatti 2007: 8).

De acuerdo con Jorge Dubatti, la realidad teatral en la actualidad se caracteriza por una voluntad desclasificadora, cuyo mayor síntoma es la transteatralización, el pensar que «todo es teatro» al tener que la vida misma se traduce en constantes actos performáticos; sin embargo, el teatro reacciona ante la posibilidad de la transteatralización y la voluntad desclasificadora cercando sus alcances y sus posibilidades de ser en determinadas condiciones. En primer lugar, el ir al teatro: uno va al teatro a construir realidad y subjetividad, no para anularlas. El asistir al teatro implica 
presencia y percepción, acontece en un espacio y tiempo determinados, y se expresa a través de acciones físicas o verbales producidas por un cuerpo ante otro(s) que percibe(n) y mira(n). Este espectador es protagonista también del ejercicio escénico: su presencia es esencial. No se trata de una presencia que solo mira, sino que completa y genera. Se trata tanto de la presentación de un hecho escénico como de las implicancias del mismo: la convivencia; la poiesis - que es la producción de sentido que se da en la puesta, ya sea a nivel macro o micro-, es decir, a nivel del montaje en total o a nivel de los sentidos y significados que los cuerpos de los actores producen, o los sentidos que los que generan los espectadores; y la espectación, que es la toma de conciencia de las implicancias del acontecimiento teatral, los factores que han determinado que la obra o montaje como producto sea puesto ahí con la noción de que se trata de algo diferente de la vida, un «otro» espacio; y que sobre eso se pueda construir sentidos y elaborar subjetividades:

El término poiesis involucra tanto la acción de crear - la fabricacióncomo el objeto creado - lo fabricado-. [...] La poiesis es acontecimiento y en el acontecimiento $y$, a la vez, es ente producido por el acontecimiento. La poiesis teatral se caracteriza por su naturaleza temporal efímera; no obstante, su fugacidad no le confiere menos entidad ontológica. La función primaria de la poiesis no es la comunicación, sino la instauración ontológica: poner un acontecimiento y un objeto a existir en el mundo (Dubatti 2007: 38).

Estas tres dinámicas propiciadas en la espectación del acontecimiento teatral y las dinámicas del observar que propugnan el cine o la televisión son claramente diferentes. La espectación de un acontecimiento teatral es única según cada vez que se vea la obra, se da en un momento particular y refuerza el vínculo social con la no reproducción de lo mimético para generar nuevos sentidos. Nuestro particular interés por las dinámicas de la espectación surge de la naturaleza problemática del teatro, y partimos de la idea de que la puesta en escena como tal ha de ir hacia el no saber, hacia lo real a través de los propios mecanismos teatrales para alejarse de lo mimético. Esto no garantiza que se «diga» lo real, pues la posibilidad de ser simbolizado está «dicha a medias». Sobre este punto trata la siguiente sección de nuestro trabajo.

\section{La puesta en escena del no saber: atravesamiento del fan- tasma $(\$ \nabla a)$}

El saber del teatro es algo que radica en su propia naturaleza, los mecanismos que emplea y las dinámicas que propicia. Ese saber no está referido a la comunicación de un saber en específico, o a pasar un conocimiento al sujeto que especta, sino que se trata de un reconocimiento de que el 
otro tiene sus propias herramientas para decodificar y resignificar lo puesto en escena:

La espectación no se limita a la contemplación de la poiesis, sino que además la multiplica y contribuye a construirla: hay una poiesis productiva (generada por el trabajo de los artistas) y otra receptiva; estas se estimulan y fusionan en el convivio y dan como resultado una poiesis convivial (Dubatti 2007: 42) (énfasis nuestro).

En ese sentido, el espectador como sujeto ante la imagen, en la dinámica de escena/espectación, no ha de ser constituido como un objeto. En la práctica teatral, consideramos que se trata de un sujeto que apunta al otro en tanto sujeto, en vía de construir intersubjetividad, y no como $a$; es decir, como objeto. No se trata de comunicar algo, con las diferentes variables políticas o de interpretación que esto determine, sino de «atravesar» el fantasma $(\$ \diamond$ a) que sostiene la idea del espectador como único y homogéneo, que no resemantiza lo visto, que solo recepciona. Esta relación de sujeto y objeto - en particular, el objeto a lacaniano - es lo que creemos que se da en el teatro que considera al espectador como un objeto, puesto ahí para «mirar» lo montado en escena, para transmitirle un supuesto conocimiento particular, o para reproducir estereotipos y representaciones simbólicas.

Como parte de esta tendencia de cierto teatro podemos referirnos al caso contemporáneo del Colectivo Teatral Víaexpresa ${ }^{1}$, particularmente a la puesta en escena de Madrugada ${ }^{2}$. La obra nos acerca a la condición de Cirilo, joven cusqueño que viene a Lima a buscar a Lucinda, de quien está enamorado y con quien debe unirse en un ritual tradicional en su pueblo para avalar su unión. Cirilo, ayudado por Wilson, iniciará un no poco accidentado recorrido en busca de su amada, en el que conocerá las diversas caras de la noche limeña, pues se desplazan, literalmente, de fiesta en fiesta, construyendo así un retrato de la sociedad capitalina, en la que conviven diversas clases sociales y en la que los jóvenes son los grandes artífices de su destino. También se plantea la idea de la oposición de la lógica campo-ciudad; tópico harto recurrente en diversas manifestaciones artísticas nacionales. El marco referencial de estos desplazamientos espaciales es la proyección de un video a modo de cortometraje, que nos remite a pensar en un video documental. Mencionamos líneas arriba la desdelimitación del teatro actual, en la medida en que establece un

1 Colectivo de directores de teatro que inició sus actividades en 2011 en el Auditorio AFP Integra del MALI como sede central. Integran Víaexpresa: Mariana de Althaus, Sergio Llusera, Diego López y Jorge Castro.

2 Concepto y dirección de Diego López, dramaturgia de Gilberto Nué. 
diálogo con otras disciplinas visuales e incorpora elementos no tradicionales. En el ejemplo en cuestión, la intermediación tecnológica se ha capitalizado en la medida en que sin la proyección gran parte de la puesta pierde sentido. El tono documental es referencial y cuasi metonímico, en alusión directa a la sociedad. Se trata, entonces, a grandes rasgos, de un teatro sin metáforas: ¿es acaso el teatro un espejo inmediato y no un traductor de experiencia? Madrugada no apela a un lenguaje «otro», garante de nuevos saberes, sino que reproduce el lenguaje de los medios masivos de comunicación, de discursos como el de la televisión o el periodismo, por ejemplo. De los discursos de la posmodernidad. No hay mediación metafórica, no construye un universo de significado, no invoca a pensar ni a saber. En ese sentido, esta puesta en escena se distancia de la ruptura de la relación sujeto-objeto y más bien la refuerza, reproduciendo los estereotipos sociales y la ideología de los medios masivos de comunicación. Pone en escena un saber que ya se sabe, que los medios y las políticas de Estado plantean hacer perdurar; por ello, el espectador es pasivo ante este tipo de montajes, como si de la televisión o del cine se tratara.

Pensar la posibilidad de plantear la relación escena-público a partir de la fórmula del fantasma $(\$ \Delta \mathrm{a})$ implica que llamemos espectador no al individuo que va a ver un espectáculo, pues ese es el hombre como ciudadano, y el teatrista no puede construir un ideal de «espectador»; sino al sujeto que tradicionalmente se toma como objeto y para quien también lo puesto en escena constituye su objeto. Partiendo de la idea de un espectador tradicional, objeto del teatrista ${ }^{3}$ (algo así como si en literatura se habla del «fantasma de la nación cercada»: aquí hablamos del fantasma del único espectador); oponemos la idea como una salida a ese esquema que, a nuestro parecer, es limitante, y proponemos como salida a ello un atravesamiento del fantasma de la relación teatrista-espectador; para la producción de una emancipación del espectador $-y$, por qué no, del teatro mismo-, en los términos de Jacques Rancière.

\section{Hacia un teatro emancipado. Resistencia}

La emancipación trata de una comprensión de que la observación y el mirar también es constructor de sentidos; es en cierta medida un actuar y no un ejercicio del dominado. Quien mira también distribuye sensibilidades:

La emancipación [...] comienza cuando se vuelve a cuestionar la oposición entre mirar y actuar, cuando se comprende que las evidencias

3 El teatrista, en la cosificación de su espectador, asume determinadas posturas éticas y políticas; perpetúa el orden simbólico excluyente de la sociedad y pone ante los ojos de quien ve una creación vacía. Esto se aprecia en el caso del ejemplo mencionado. 
que estructuran de esa manera las relaciones del decir, del ver y del hacer pertenecen, ellas mismas, a la estructura de la dominación y de la sujeción [...] El espectador también actúa [...] Observa, selecciona, compara, interpreta. Liga lo que ve con muchas otras cosas que ha visto en otros escenarios, en otros tipos de lugares [...] los espectadores ven, sienten y comprenden algo en la medida en que componen su propio poema, tal y como lo hacen a su manera actores o dramaturgos, directores de teatro, bailarines o performistas (Rancière 2010: 19).

El espectador emancipado, según Rancière, participa con una mirada activa que pone en juego su acervo, su ideología, sus modos de pensar y sus propias experiencias. Nosotros nos inclinamos por considerar que un espectador emancipado de la espectacularización, que ponga en juego subjetividades a partir de lo visto, no puede surgir sin la aparición de un teatro emancipado, que quiebre la relación cosificadora de la que tratamos en la sección anterior. Parte del atravesamiento del fantasma y de la ruptura de la relación embrutecedora - que pretende transmitir lo idéntico - supone dar relevancia al aspecto convivial del teatro, y este punto es el límite, por así decirlo, de la «libertad del espectador», que crea e interpreta con libertad, pero también en compañía. La idea de un teatro emancipado, que rompa la relación fantasmática entre escena y espectador desde su misma concepción y que se desligue de las otras formas del espectáculo, como el cine o la televisión, nos lleva a pensar en él como un espacio de resistencia ante lo posmoderno.

La emancipación en términos del autor de El espectador emancipado nos parece restrictiva. Rancière evade lo convivial y más bien lo niega; pero es valioso también su aporte en busca de una espectación que se aleje de lo programático, de la transmisión de lo mismo de un lado de la escena al otro. De ahí que tomemos su propuesta también para trazar las líneas referenciales de lo que podría ser un teatro emancipado, ya que creemos que la emancipación supuesta habría de venir de ambos lados. Mientras la cultura del espectáculo prime, no podremos acceder a una verdadera emancipación de la mirada:

El poder común a los espectadores no reside en su calidad de miembros de un cuerpo colectivo o en alguna forma específica de interactividad. Es el poder que tiene cada uno o cada una de traducir a su manera lo que él o ella percibe, de ligarlo a la aventura intelectual singular que los hace semejantes a cualquier otro en la medida en que dicha aventura no se parece a ninguna otra (Rancière 2010: 22) (énfasis nuestro).

Creemos que, al menos en el teatro y en las dinámicas particulares de espectación que supone, no puede evadirse lo convivial y no solo en el 
sentido de que hay una interacción con otros cuerpos o hay un cúmulo de presencias físicas entre el público; sino también porque una puesta en escena implica un trabajo previo no solamente de actores, sino de técnicos, dramaturgos y músicos, que han dado forma al producto final y que intervienen en él día a día durante la temporada. Por eso, si bien creemos en la emancipación de la mente de quien ve, en tanto se desliga de idearios colectivos y participa con su propia subjetividad, consideramos que una condición ineludible es la convivial, y que, más bien, debido a que en primer lugar la escena - el montaje - es productor de sentidos, se alza la idea de un teatro emancipado, que rompa la relación fantasmática entre escena y espectador desde su misma concepción, y que se desligue de las otras formas del espectáculo, como el cine o la televisión. Esta idea nos lleva a pensar en el teatro emancipado como un espacio de resistencia ante lo posmoderno.

La puesta en escena del no saber (en tanto no se trata de un paso de un conocimiento único) constituye un reconocimiento de las facultades del espectador emancipado, sujeto político por excelencia; y también del teatro emancipado, que reconoce que no hay un solo saber y que apela al convivio para traducir experiencia y generar subjetividades; y que, además, con sus otros mecanismos (territorialidad, heterogeneidad, etc.) se opone/resiste y se mantiene ante la posmodernidad.

Toda puesta en escena preserva el vínculo geográfico-cultural, ya que, al compartir el mismo espacio y estar situados en el mismo territorio, estamos ante una manifestación cultural viva y única; que dialoga con los espectadores y con su tiempo. En la espectación hay un hecho objetivo, que no cambia -independientemente de las interpretaciones o saberes que pueda generar el espectador-, y este es que lo puesto en escena es la instauración de un mundo, en un momento, una historia y territorio determinado, y no en una especie de zona indeterminada. No podríamos así considerar arbitraria la poiesis de la espectación; hay límites, no para el pensamiento del espectador, sino de las condiciones, de la coyuntura, de lo acordado por convención y de la convivencia in situ. La siguiente cita es clara al respecto:

[...] el teatro es compañía (el regreso a la subjetividad ancestral del «compañero»), una actividad consciente y colaborativa sostenida en el diálogo y encuentro con el teatro. La compañía exige, a su vez, amigabilidad y disponibilidad hacia el otro (por lo que no sería sustentable una definición teórica del teatro como acontecimiento solipsista o exclusivamente interno, confinado a la actividad craneal del espectador) (Dubatti 2007: 52). 
Así, la poiesis que se crea dentro de ese espacio de convivencia se remite a la fabricación de significados y metáforas «otros», con reglas propias en el mundo representado; la escenificación, entonces, no necesariamente habría de remitirse a la simple representación mimética, sino emplear elementos que rompan la relación sujeto-objeto que hemos referido. Debe exigir un espectador atento y consciente, que se adapte al ritmo y al caos ordenador de la obra misma, que vaya creando significado, así como la puesta crea significados ante ellos. El teatro visto ya no como espejo inmediato de la realidad, sino como traductor de experiencia en convivio.

La excepcionalidad del acontecimiento teatral se relaciona con aquello singular que el teatro produce en convivio, que es la reunión, el encuentro de un grupo de hombres y mujeres en un punto del espacio y del tiempo. Es una conjunción de presencias e intercambio humano directo, sin intermediaciones técnicas ni delegaciones que posibiliten la ausencia de los cuerpos. No se va al teatro para estar solo: el convivio es una práctica de socialización, de afectación grupal; empero, claro, resguardando que el sujeto que especta siente por sí mismo y que, a la vez, en el refuerzo del vínculo vicario, puede llegar a sentir con los otros. Y es aquí donde nos encontramos frente a lo que hemos denominado el límite de la espectación, en relación con el espectador emancipado que propone Jacques Rancière, en la medida en que no podemos negar el aspecto de la convivencia frente a lo que espectado supone. Este límite lo es a la vez del sentido, de acuerdo con la idea de que una puesta en escena y sus implicancias conviviales son una puesta en escena del sentido. Y, más allá de ella, si tomamos lo propuesto por Rancière, de derribar la idea del teatro como hecho comunitario, perdemos de vista la relevancia de la experiencia para la construcción de la subjetividad; de ahí que consideremos la propuesta de Rancière como contrapuesta ante lo que asumimos: el teatro sí es comunitario por sí mismo.

Consideramos también que hay una diferencia entre el teatro y el espectáculo que tiende al entretenimiento; espectáculos tales apelan a la risa fácil, a los vicios sociales y bromas comunes que suelen reproducir tramas cuasi miméticamente con respecto de la realidad, generando así un espacio de diversión, mas no una invitación al pensamiento. La emancipación en términos de Rancière nos parece restrictiva y limitada por las razones ya expuestas, pero es valioso también su aporte en pos de una espectación que se aleje de lo programático, de la transmisión de lo mismo de un lado de la escena al otro. De ahí que tomemos su propuesta también para trazar las líneas referenciales de lo que podría ser un teatro emancipado, ya que creemos que la emancipación supuesta habría 
de venir de ambos lados. Mientras la «cultura del espectáculo» prime, no podremos acceder a una verdadera emancipación de la mirada.

\section{Apuntes finales}

El poder del espectador radica en la posibilidad de (como individuo y como miembro de una colectividad) cuestionar su mirada y revelarse contra ese saber impuesto para generar el suyo propio. De acuerdo con Jorge Dubatti, consideramos que el teatro puede ser pensado como un espacio de resistencia. Esta idea está intrínsecamente ligada a la concepción del teatro como espacio político, que pone en escena no lo ya ahí, sino aquello que no se ve. La demanda de un espectador emancipado ${ }^{4}$, pues, está también ligada a la aparición de un teatro emancipado, que piense su hacer y que constituya su lenguaje como un medio de resistencia, y en este sentido podríamos afirmar que se trata de una oposición a lo posmoderno; ya que se rechaza la idea de desterritorialización, que propugna la configuración de espacios universales: en el teatro no podemos hablar de espacios universales; un acontecimiento teatral responde a su época y a su contexto y es ahí donde debe ser pensado, mientras que la posmodernidad y la exaltación de las redes de comunicación defienden la desterritorializacion como algo positivo. El teatro preserva el encuentro de presencias, de convivencia; y en ese sentido se habla de lo aurático en el teatro, que sin intermediación técnica propicia el encuentro con los otros, a diferencia de la televisión. El teatro también está en contra de la globalización y de la homogeneización de los individuos supuestamente iguales todos. Ante esto, un teatro emancipado habría de considerar al espectador como individuo en su diferencia, en su singularidad; desligándose de ese saber embrutecedor y dando paso así a la ruptura de la relación sujeto-objeto. El teatro emancipado, por último, habrá de alzarse contra la univocidad del pensar y de lo real, porque, como un lenguaje ilimitado, sus propuestas metafóricas serán múltiples y complejas: ampliaciones del mundo a través del despliegue de otras ficciones.

La puesta en escena del no saber constituye un reconocimiento de las facultades del espectador emancipado, sujeto político por excelencia; y también del teatro emancipado, que reconoce que «no sabe» y que apela al convivio para traducir experiencia y generar subjetividades. El rol de la espectación en el acontecimiento teatral es importante, uno de los ejes principales sobre los cuales debe construirse una puesta que se tenga como tal, emancipada, pensante y que no recurra a embrutecer su hacer y

4 No mencionamos la palabra compañero añadida a la frase, pues consideramos que la relación ya es intrínseca. 
embrutecer a quienes espectan. La experiencia y la subjetividad, por su parte, generadas en convivo, suponen una limitación para la propuesta de Rancière, quien excluye lo comunitario en la espectación. Ante esto nos queda cuestionar si es que se trata realmente de un límite, o de una carencia para pensar al teatro tal como él es, subjetivo, experiencial y ante todo convivial.

Mario Vargas Llosa, en su más reciente libro de ensayos, La civilización del espectáculo, propone que el capitalismo, el rol del mercado y la influencia de los medios de comunicación han hecho que el hombre deje de ser individuo y se masifique, que obedezca las leyes del gran Otro del Mercado y del capital, y que anule sus capacidades como sujeto. Este fenómeno de la masificación, e incluso la deshumanización del hombre, es posible de ser enmarcada en la posmodernidad, etapa que replica los ideales de la modernidad y que exacerba la apariencia de individualismo bajo una lógica homogeneizadora que oprime las libertades del sujeto, pues el mercado y los medios masivos de comunicación controlan el devenir de la vida en sociedad y los impulsos de los hombres, de modo que terminan por ser parte de una masa única, que busca la premura del placer simple, fútil y que se diferencia de la sociedad anterior por el afán de inmediatez y la producción de productos «culturales» en abundancia, privilegiando la cantidad en vez de la calidad:

La diferencia esencial entre aquella cultura del pasado y el entretenimiento de hoy es que los productos de aquella pretendían trascender en el tiempo presente, durar, seguir vivos en las generaciones futuras, en tanto que los productos de este son fabricados para ser consumidos al instante y desaparecer, como los bizcochos o el popcorn (Vargas Llosa 31).

Vargas Llosa mira con pesimismo esta nueva realidad a la que denomina civilización del espectáculo, en la que uno de los principales valores es el entretenimiento y el pasarlo bien se ha constituido como el valor supremo. Ese es uno de los puntos clave que critica el autor, ya que se ha devenido en la banalización de lo cultural, alimentado también por el escándalo mediático y la chismografía periodística. Se refiere también a que la democratización de la cultura ha tenido un efecto adverso, que es el considerar que ahora «todo es cultura». Si bien no estamos de acuerdo con la totalidad de esta propuesta principal del autor, nos interesa, finalmente, resaltar que la civilización posmoderna es colegible con la civilización del espectáculo; y de ahí cierta denotación peyorativa del término, pues se trata de una forma de entretenimiento intrascendente. Consideramos que no solo por banal, como afirma Vargas Llosa, sino por lo mencionado líneas arriba sobre la perpetuación de los modos de vivir y de pensar en la sociedad posmoderna. 


\section{REFERENCIAS BIBLIOGRÁFICAS}

DUBATTI, Jorge (2007). Filosofía del teatro I. Buenos Aires: Editorial Atuel. rial Libros de Godot.

Introducción a los estudios teatrales. México D. F.: Edito-

EVANS, Dylan (1997). Diccionario introductorio al psicoanálisis lacaniano. Buenos Aires: Ediciones Paidós.

SARLO, Beatriz (2004). Escenas de la vida posmoderna. Buenos Aires: Editorial Seix Barral.

RANCIÈRE, Jacques (2010). El espectador emancipado. Buenos Aires: Ellago Ediciones.

VARGAS LLOSA, Mario (2012). La civilización del espectáculo. Lima: Editorial Alfaguara. 